\section{Looking back on a prosperous year 2014}

Gattaz WF/ Arch Clin Psychiatry. 2014;41(6):137

DOI: 10.1590/0101-60830000000030

\section{Dear Readers,}

In the Editorial of the issue $4^{1}$, I had the pleasure to share with you the rise of our Thomson Reuters Impact Factor (ISI) of almost $40 \%$ (currently 0.89 ).

But, that was not all yet. As shown just now, we have also achieved an impressive increase of our SCImago Journal Rank (SJR) impact factor of almost $100 \%$ from 0.63 to currently 1.23 . According to this ranking, the Archives of Clinical Psychiatry has entered in the top 10 the most important scientific journals in Brazil and takes second place in the filed of Psychiatry and Mental Health in Latin America.

Looking back on this prosperous year, I would like to thank, once more, the Editorial Team, the Section Editors and their Assistant Editors, the members of the Editorial Board, and the external reviewers (listed in this issue) for their support, which allowed us to obtain this achievement. But above all, we are most indebted to our authors, who gave us the opportunity to publish their high quality manuscripts, which are the base for the Archives editorial success.
For the coming year, we will not spare any efforts to maintain the high standards of our publication, allowing our authors a rapid vehicle to communicate their data to our selected readership.

In that spirit, I'm looking forward to a successful new year and wish all of you and your families a Merry Christmas!

My warmest regards,

Wagner F. Gattaz
Editor-in-Chief

\section{Reference}

1. Gattaz WF. Editorial announcement regarding new impact factor and title change. Rev Psiq Clín. 2014;41(4):89. 